\title{
A Preliminary Study on EFL Students' Grammatical Competence in Descriptive Writing Task
}

\author{
Hanna Juliaty \& Demus Abetnego \\ hanna.juliaty@ukrida.ac.id; demabednego@gmail.com \\ Department of English, Universitas Kristen Krida Wacana, Jakarta
}

\begin{abstract}
This study aims to identify and examine the ill-formed sentence construction in a descriptive text produced by Indonesian senior high school students, focusing on eight grammatical categories classified by James (1998): prepositions, articles, singular and plural nouns, adjectives, irregular verbs, tenses, concord and possessive case. The study used qualitative research and text analysis to examine five senior high school students' descriptive texts. The findings showed that there were seven grammatical categories occurred in the ill-formed sentence construction in the students' descriptive texts. Those grammatical categories include prepositions, articles, singular and plural nouns, adjectives, tenses, concord and possessive case. In addition, this study also found that the most frequently occurred ill-formed sentence construction in the descriptive text appeared in the grammatical forms of articles, tenses and concord.
\end{abstract}

Keywords: descriptive text, English as a foreign language, grammar

\section{Introduction}

Writing skill is an important part of students' academic life because writing allows them to organize ideas and feelings clearly, as well as to convey meaning in written communication (Afrin, 2016). Despite its importance, writing is often considered as the hardest skill to acquire in second language and foreign language learning (White \& Arndt, 1991). This might be due to the fact that writing is not simply an instant product; in fact, it is a complicated process, especially in EFL writing practice, as learners are required not only to brainstorm and organize their ideas or opinions, but also to apply the correct L2 grammar to convey comprehensible information or knowledge to the reader (Davies \& Pearse, 2000). Consequently, writing requires students to have extensive concentration and writing skill for composing and developing ideas into a proper written text. For this reason, EFL writing has been a challenging and difficult subject to teach by teachers and to learn by students in many EFL classrooms.

In L2 writing, EFL students are required to apply basic skills and high-level skills. The basic skills consist of handwriting or typing, spelling, constructing grammatical sentences and punctuating, while the high-level skills include cognitive skills, such as gathering ideas, organizing and sequencing, structuring, drafting and editing (Nunan, 1999). For many EFL students whose English proficiency is still in the beginner or intermediate level, most of the writing practices focus on the basic skills, particularly in applying correct grammar in sentences.

During a two-month teaching internship program undertaken by the second author at an Indonesian private school in Jakarta, it was evident that the senior high school students often struggled and had difficulties in writing, 
mainly in constructing grammatically correct sentence structure. Improving the L2 writing practice of EFL learners in secondary level is necessary as writing lessons in this level can be a foundation for students to learn creative, academic and formal writing, which will be useful in their future endeavors. For this reason, this study was conducted to examine Indonesian senior high school students' L2 writing difficulties, mainly in the grammatical categories shown in their ill-formed sentence construction.

Ill-formed sentence construction in learners' L2 writing may result from omission, addition and selection (Ellis, 1997). Omission occurs when learners omit some necessary parts of words or morphemes in the sentence. Addition occurs when learners add some unnecessary or redundant parts of words in the sentence. Selection occurs when learners use incorrect word forms in the sentence. These errors that students make in writing may lead them to produce ill-formed sentence construction. James (1998) classifies eight grammatical categories that learners tend to make errors in, which includes prepositions, articles, singular and plural nouns, adjectives, irregular verbs, tenses, concord, and possessive case.

In order to examine ill-formed sentence construction that learners make in writing, Contrastive Analysis (CA) theory is often used. Contrastive Analysis is used to analyze ill-formed sentence construction and errors by comparing the similarities and differences between L1 and L2 (Al-Khresheh, 2016). In language learning, CA is positioned in the behaviorist perspective, which perceives learning as a mechanical process of habitual formation. CA views that L2 learning process comes from a new establishment of L2 habit instilled by L1 (Ellis \& Barkhuzien, 2005).

There have been many studies on illformed sentence construction conducted to investigate learners' grammatical competency as shown in their L2 writing production. For example, in EFL context, recent studies on this matter can be found in Bangladesh, Thailand and Indonesia.
In Bangladesh, the ill-formed sentence construction occurring in students' descriptive paragraph include subject-verb agreement, article, preposition, sentence fragment and verb tense (Afrin, 2016). In Thailand, a major problem in L2 writing that Thai students encounter is mostly influenced by the negative transfer of their L1 into L2 (Kaweera, 2013). In other words, Thai students keep relying on their L1 structure when producing L2, which results in the illformed sentence construction. On the other hand, in Indonesia, students tend to make illformed sentence construction in the form of subject-verb agreement and article (Mustafa et al., 2016).

Those previous studies show that the grammatical categories in which ill-formed sentence construction takes place in EFL learners' writing production are varied and tend to be different in many cases. Hence, more studies on this topic are necessary to be conducted.

\section{Method}

This study aims to investigate the illformed sentence construction in a descriptive text written by Indonesian students from a private senior high school in Jakarta. The study used qualitative research and textual analysis method.

There were five students from Grade 11 participating in the study. They were chosen based on the recommendation made by their English teacher. According to the teacher, the students' English grades were varied.

The five students were asked to write a descriptive text of approximately 300 words, describing either their family or their school library. The options for the two topics were intentionally selected because the students were very familiar with both topics and thus, it might facilitate them better in writing. The descriptive writing task was assigned to the students during the exam weeks in November 2017 and they were allowed to complete the writing task within two weeks at maximum. When they finished the task, they submitted the writing via email. 
After the students' writings were collected, the data were analyzed using several steps. Firstly, the descriptive texts were reread a few times. Secondly, the illformed sentence construction in the texts was identified and coded. Thirdly, the coded illformed sentence construction was listed and classified into a table based on James' (1998) classification of grammatical categories that learners tend to make errors in. Fourthly, the frequency was calculated in order to see which grammatical forms occurred the most and least dominantly in the students' descriptive texts. Finally, the grammatical categories influencing the ill-formed sentence construction were analyzed and interpreted.

\section{Discussion}

The findings showed that there were seven grammatical categories occurring in the students' descriptive texts. These grammatical categories consisted of prepositions, articles, singular and plural nouns, adjectives, tenses, concord and possessive case. On the other hand, there was no grammatical aspect found in the form of irregular verb in the students' ill-formed sentence construction.

Furthermore, from the calculation table, the most dominant categories found in the data were articles and tenses, while the least occurred ones were adjectives, prepositions and possessive case. The recapitulation of all grammatical categories influencing the illformed sentence construction in the students' descriptive text is presented in Table 1 and is discussed in the following subsections.

Table 1. Frequency of Incorrect Grammatical Forms

\begin{tabular}{|c|c|c|c|c|c|c|c|}
\hline \multirow{10}{*}{$\begin{array}{c}\text { Grammatical } \\
\text { Categories }\end{array}$} & Classification & S1 & S2 & S3 & S4 & S5 & Total \\
\hline & Prepositions & 0 & 1 & 0 & 2 & 0 & 3 \\
\hline & Articles & 4 & 2 & 0 & 0 & 2 & 8 \\
\hline & Singular and plural nouns & 3 & 0 & 0 & 1 & 2 & 6 \\
\hline & Adjectives & 1 & 0 & 0 & 0 & 1 & 2 \\
\hline & Irregular verbs & 0 & 0 & 0 & 0 & 0 & 0 \\
\hline & Tenses & 2 & 0 & 1 & 3 & 2 & 8 \\
\hline & Concord & 3 & 0 & 0 & 0 & 4 & 7 \\
\hline & Possessive case & 1 & 0 & 0 & 0 & 3 & 4 \\
\hline & \multicolumn{6}{|c|}{ Total of Incorrect Grammatical Forms } & 38 \\
\hline
\end{tabular}

\section{Prepositions}

From the data, two students (S2 and S4) made ill-formed sentence construction in the form of prepositions. The ill-formed sentence construction that the students made is listed as follow:

Table 2. Incorrect Grammatical Construction in the Form of Prepositions

\begin{tabular}{cl}
\hline Student & \multicolumn{1}{c}{ Sentence } \\
\hline S2 & 1. Most students prefer to visit the canteen from library. \\
\hline S4 & $\begin{array}{l}\text { 2. This is my second-year study at there. } \\
\text { 3. Beside for teaching, the library also can use for meeting. }\end{array}$ \\
\hline
\end{tabular}

In sentence $1, \mathrm{~S} 2$ intended to express that most students in his school liked to go to canteen more than to visit the library. Here, he intended to present a comparison that the canteen was more preferred by the students than the library. In doing so, he used the 
preposition from to point to the library after the phrase prefer to visit the canteen.

In L2 structure, the phrase prefer is always followed by prepositions to or over to indicate preference. Since S2 used preposition from instead of to or over after the word prefer in the sentence, the sentence became grammatically incorrect. A proper correction to the sentence can be 'Most students prefer to visit the canteen to the library' or 'Most students prefer to visit the canteen over the library'. In S2's L1 system, the word prefer ('lebih memilih') is usually followed by a noun or a verb and a preposition 'dari' or 'daripada' (e.g. 'Saya lebih memilih $A$ dari $B^{\prime}$ ). The preposition 'dari', when being translated into English, becomes from. Hence, S2 applied the L1 rule in sentence 1 and wrote prefer... from instead of using the L2 rule and applied prefer... to or prefer... over.

On the other hand, in sentence 3 , S4 used preposition beside to show another function of the library, which was used not only for teaching activities, but also for meetings. In L2 structure, the preposition beside is used to give information that a noun is physically or figuratively located next to or at the side of another noun. In the sentence, the student used the preposition beside not to specify a location and hence, the use of the preposition in the sentence was incorrect. As the intention of the student was to express an additional function of the library, she should have used the preposition besides instead of beside.
Although these two prepositions seem similar, they contain significantly different meanings. Beside, as mentioned previously, means next to or at the side of and is used to indicate a location. Besides, on the other hand, means in addition to or also and in the sentence was meant to indicate additional information about the subject. Hence, the preposition used in the sentence should have been besides.

In S4's L1 system, the words or phrases used to indicate beside and besides are similar and can be used interchangeably (i.e. L1 preposition 'di samping' can be used both to indicate that a noun is located next to another noun, as well as to indicate an additional information in a sentence, e.g. 'di samping $i t u$ '). This L1 pattern that S4 has been familiar with might have interfered with her understanding on L2 preposition rule, particularly on the use of beside and besides. Consequently, this has led the student to make an ill-formed sentence structure by applying incorrect preposition.

\section{Articles}

From the data in Table 1, three students (S1, S2 and S5) made ill-formed sentence construction in the form of articles. The illformed sentence construction that those students made is listed as follow:

Table 3. Incorrect Grammatical Construction in the Form of Articles

\begin{tabular}{ll}
\hline Student & \multicolumn{1}{c}{ Sentence } \\
\hline S1 & $\begin{array}{l}\text { 1. The library also has newspaper for someone that want to know about a current news. } \\
\text { 3. You may pay fine for it. } \\
\text { 4. You can request for the new book that you want to read. }\end{array}$ \\
S2 $\quad \begin{array}{l}\text { 5. Most students prefer to visit the canteen from library. } \\
\text { 6. In fact, the library is a good place to learn. }\end{array}$ \\
S5 $\begin{array}{l}\text { 7. I always go to library to study for test. } \\
\text { 8. I always go to library. }\end{array}$
\end{tabular}

Based on the data, the students frequently omitted or added improper articles to certain nouns in their sentences, which resulted in several ill-formed sentence constructions.
Examples where the students inappropriately omitted an article in the sentences can be found in sentences $2,3,5,7$ and 8 . 
In sentences 2 and 3, S1 should have put indefinite articles, i.e. article an before the underlined noun air conditioning (sentence 2) and an article $a$ before the underlined noun fine (sentences 3) because both nouns were singular and did not refer to anything specific; the nouns air conditioning and fine referred to air conditioners (AC) and fine in general and hence, an indefinite article should have been inserted before those nouns. On the other hand, in sentences 5, 7 and 8, S2 and S5 should have added definite article the before the underlined noun library because the sentences were referring to a specific library, which was their school library.

Moreover, examples where the students incorrectly added an article in the sentences can be found in sentences 1,4 and 6 . In sentence $1, \mathrm{~S} 1$ added an indefinite article $a$ to the underlined noun phrase current news. The indefinite article $a$ and $a n$ are used for singular nouns or noun phrases. In sentence 1 , the underlined noun phrase current news was not a singular noun; instead, it was an uncountable noun phrase. In L2 system, articles are not applied before uncountable nouns or noun phrases. Hence, in sentence 1, the student should have omitted the article $a$ before the noun phrase current news.

In contrast, in sentences 4 and 6, S2 and S5 improperly added the article the before the underlined nouns new book and library. This would have been grammatically correct if those nouns referred to a specific new book and a specific library i.e. their school library.
However, in this sentence, the nouns were not meant to be referred to a specific new book or a specific library; instead, the nouns the new book and the library were intended to be referred to any new book and any library in general because before these sentences, the students did not mention any new book and library at all. Since the nouns new book and library were mentioned for the first time in the sentences, the nouns should have used the indefinite article $a$ instead of a definite article the.

In L2 structure, articles are consistently used in sentences and improper omission or addition of them in sentences can cause illformed sentence construction. In contrast, in the students' L1 system, various articles used to specify nouns are not consistently used in L1 sentence structure. As a result, when the students write in L2, their L1 structure often still interferes during the process and causes them to apply a particular article incorrectly. In addition, the incorrect article use in the sentences may possibly be caused by the students' incomplete understanding about the L2 rules on the use of indefinite and definite articles to particular nouns.

\section{Singular and Plural Nouns}

From the data, there were three students (S1, S4 and S5) who made ill-formed sentence construction in the form of singular and plural nouns. The ill-formed sentence construction that the students made is listed as follow:

Table 4. Incorrect Grammatical Construction in the Form of Singular and Plural Nouns

\begin{tabular}{|c|c|}
\hline Student & Sentence \\
\hline S1 & $\begin{array}{l}\text { 1. The library is very clean and have many book in there. } \\
\text { 2. You can borrow some book for read from sir Japon } \\
\text { 3. The library also has some computer. }\end{array}$ \\
\hline S4 & 4. One of my hobby is reading a book. \\
\hline S5 & $\begin{array}{l}\text { 5. My brother is } 33 \text { year old. } \\
\text { 6. She is } 32 \text { year old. }\end{array}$ \\
\hline
\end{tabular}

In Table 4, S1 made ill-formed sentence construction by not synchronizing the nouns with their quantifiers (sentences 1-3). The quantifiers used in those sentences, which are many and some, indicate that the nouns they modified are plural. Thus, the nouns should have been written in plural form with the suffix $-s /$-es at the end of the nouns, i.e. many 
books, some books and some computers. Since S1 used quantifiers for plural nouns, yet he did not synchronize them with plural nouns afterwards, consequently the sentences became grammatically incorrect.

In contrast, $\mathrm{S} 4$ in sentence 4 mistook the noun following the phrase 'one of ...' as a singular noun and hence, used a singular noun at the end of the phrase, i.e. one of my hobby. In L2 structure, the noun following the phrase 'one of...' is actually always plural. Therefore, the sentence was grammatically incorrect and can be corrected into 'One of my hobbies is reading a book.'

Similarly, in sentences 5-6, S5 did not synchronize the noun year with its plural determiners. In those sentences, the determiners show plural numbers, i.e. 33 and 32; hence, the noun year that follows those determiners should have also been plural, i.e. 33 years old and 32 years old.

In the students' L1 system, various quantifiers and determiners are available, both for singular and plural nouns. However, these quantifiers and determiners are only followed with singular nouns because the L1 does not have plural form for nouns. Thus, in L1 sentences, the part that determines whether a noun is singular or plural is not in the form of the noun itself, but in the form of quantifier or determiner attached to it (e.g. 'sebuah buku' $\rightarrow$ a book; 'beberapa buku' $\rightarrow$ some books). This L1 rule on singular and plural noun seemed to be applied and transferred by the students when they were writing in L2. This shows that they might not have complete awareness of the distinctive rule of singular and plural noun in L1 and L2. As a result, this led them to apply their L1 rule in L2 sentences and caused their sentences to become grammatically incorrect.

\section{Adjectives}

From the data, two students (S1 and S5) made ill-formed sentence construction in the form of adjectives, as listed in Table 5.

Table 5. Incorrect Grammatical Construction in the Form of Adjectives

\begin{tabular}{cl}
\hline Student & \multicolumn{1}{c}{ Sentence } \\
\hline S1 & 1. The library is safety room because it has CCTV. \\
\hline S5 & 2. Although we are just a small family, our affection to each other is very large. \\
\hline
\end{tabular}

In sentence 1, S1 used incorrect word form for an adjective and caused the sentence to be grammatically incorrect. In the sentence, $\mathrm{S} 1$ intended to deliver information that the school library was a safe room because it had CCTV. However, instead of using the adjective safe to describe the library, S1 used the word safety, which is the noun of the adjective safe.

In L2 structure, each part of speech plays a crucial role in the construction of a grammatically correct sentence. In contrast, in the student's L1 system, many parts of speech have similar form and are not strictly applied in sentences. This L1 rule might have led the student to apply the same rule when writing in L2, which resulted in the ill-formed sentence construction.
On the other hand, another incorrect grammatical sentence in the form of adjective occurred in sentence 2 , where it described that S5 had a small family, yet each family member had an enormous affection towards each other. The adjective used to express the amount of affection in S5 family was large. This adjective is inappropriate because large is mostly used for concrete nouns. As affection is an abstract noun, a more appropriate adjective that can be used to express it can be great or big, i.e. '... our affection to each other is very great/big' or '... we have a great/big affection to each other'.

\section{Tenses}

From the data, four students (S1, S3, S4 and S5) made ill-formed sentence 
construction in the form of tenses. The ill-

students made is listed in Table 6.

formed sentence construction that the

Table 6. Incorrect Grammatical Construction in the Form of Tenses

\begin{tabular}{cl}
\hline Student & \\
\hline S1 & $\begin{array}{l}\text { 1. The computers use to search for something that you want to know. } \\
\text { 2. Is not reading a book a good habit that needs to be preserved? }\end{array}$ \\
\hline S3 & 3. Mr. Japon easily find out who borrowed the school's books. \\
\hline S4 & $\begin{array}{l}\text { 4. I like read a novel. } \\
\text { 5. Beside for teaching, the library also can use for meeting. } \\
\text { 6. I feel like I'm sleep at my bedroom because there is cool and cozy. }\end{array}$ \\
\hline S5 & 7. My father already passed when I was in the third grade. \\
\cline { 2 - 3 } & 8. Since that day, my mother takes his place to work.
\end{tabular}

In sentences 1 and 5, S1 and S4 applied active verb for passive sentences. Active voice is used in sentences when the subject performs the action signified by the verb. On the other hand, passive voice is used in sentences when the subject is being acted upon by the verb. From the table, S1 and S4 wrote ill-formed sentence construction as they put active verbs, i.e. use and can use, in sentences that were supposed to be passive. For instance, in sentence 5, S4 intended to deliver information that his/her school library could be used for meeting. However, he/she used the action verb in the sentence '... the library also can use for meeting'. In this sentence, 'the library' as the agent (doer of the action) was written to perform the action verb can use; hence, it indicates that the sentence is an active sentence. However, since a library is a non-living object, it cannot perform active verbs, e.g. can use. Therefore, this sentence should have been constructed in passive voice, i.e. '... the library also can be used for meeting'. In this correct structure, 'the library' functions not as the agent (doer of the action), but as the receiver of the action.

Conversely, sentence 2 is grammatically incorrect because of the wrong word order. Here, S1 intended to make an interrogative sentence in negative form. In L2 structure, a negative interrogative sentence should start with verb be or $d o$, followed by a subject and the word not. In sentence 2, S1 put verb be, the word not and the subject in sequence and hence, causing the sentence to be grammatically incorrect. The correct version of the sentence should be 'Is reading a book not a good habit that needs to be preserved?'

Furthermore, S3, S4 and S5 made several ill-formed sentence constructions in the form of tenses, i.e. past tense (sentence 3), gerund (sentence 4), present continuous tense (sentence 6), past perfect (sentence 7) and present perfect continuous (sentence 8). In these sentences, the students tried to describe events and activities in wide-ranged time settings, from the past to the present time, and hence, they might get confused about the correct tenses to use.

In the students' L1 system, there are no tenses; the same verbs are used to describe events in the past, present and future, and time markers are used to indicate whether a certain event happens in the past, the present or the future. In contrast, L2 structure strictly applies particular verb forms and time markers to indicate certain tenses, and L2 learners are required to master these rules. As the students in this study were still in the beginner and intermediate levels, they were not yet proficient in applying grammatically correct tenses in their L2 writing. As a result, they made numerous ill-formed sentence constructions in the form of tenses. 


\section{Concord}

From the data, three students (S1, S4 and S5) made ill-formed sentence construction in the form of concord. The ill-formed sentence construction that the students made is listed in Table 7.

Table 7. Incorrect Grammatical Construction in the Form of Concord

\begin{tabular}{ll}
\hline Student & \multicolumn{1}{c}{ Sentence } \\
S1 & 1. The library also has newspaper for someone that want to know about a current news. \\
2. Sir Japon is the one that take care of library. \\
3. The library is very clean and have many book in there. \\
4. Novels in library is very good to read. \\
55 She is really kind and like to help others. \\
6. Sometimes she annoy me. \\
7. He is nice even though sometimes he a little bit annoying.
\end{tabular}

Examples where the students did not synchronize the subject and the verb when they were put next to each other can be found in sentences 1, 2 and 6 . In these sentences, the subjects were singular nouns, i.e. someone, the one and she. Since the subjects were all singular and referred to events or information that were either factual or habitual, the verbs that followed them should have been in present singular form, which should be constructed by adding the suffix -s/-es to the verbs. However, the students omitted the suffix $-s /-e s$ in the verbs and hence, causing the sentences to be grammatically incorrect.

Moreover, it is important to notice that sentences 1 and 2 had a more complex structure than sentence 6 , which was considered a simple sentence since it had a subject, a verb and a complete thought. Sentences 1 and 2, on the other hand, did not simply consist of a subject, a verb and a complete thought; they contained adjective clauses that modified particular nouns in the sentences using the relative pronoun that, and therefore, the sentences appeared to be more complex. Sentences 1 and 2 had two subjectverb agreements, which were located in the beginning and in the later part of the sentences. In the beginning of the sentences, the students were able to synchronize the subject and the verb (i.e. the library also has newspaper; Sir Japon is the one...); however, when the students arrived at the later part of the sentences where they used adjective clauses to modify certain nouns, they did not synchronize the subject and the verb (i.e. newspaper for someone that want to know about a current news; the one who take care of library).

Some other examples of errors in the form of subject-verb agreement can also be found in the sentences where the students applied parallelism and ellipsis in their sentences, such as in sentences 3 and 5 . In these sentences, the students combined two clauses that provided information about the same subject, and they omitted writing the subject in the second clause because it had been mentioned in the first clause. However, the verb that they used in the second clause was not synchronized with the subject in the first clause (i.e. the library is very clean and have many book...; she is really kind and like to help others). As these sentences contained factual and habitual information, the action verbs used in the second clauses should have been written in present singular form with suffix $-s$. However, the students overlooked this rule and instead, applied the action verbs without modifying them according to the subjects in their sentences; hence, causing the sentences to have ill-formed construction.

Another example of errors in subject-verb agreement from the students' descriptive texts can be found in sentence 4 where a 
student applied a prepositional phrase between the subject and the verb. In this sentence, the subject was novels (a plural noun) with a prepositional phrase in the library, and hence, the verb that followed the subject should have been in plural form as well. Yet, instead of applying a plural verb after the prepositional phrase, the student used a singular verb (Novels in the library is very good to read). This shows that the subject novels and the verb is were not synchronized because the subject was plural, but the verb was singular. As a result, the sentence became incorrect as it contained a grammatical error in the aspect of subject-verb agreement.

In L2 structure, although the verb is placed next to the prepositional phrase of the subject (in this example, it was novels in the library), the verb should always follow the subject and not the prepositional phrase. In sentence 4, the subject novels is plural, while the prepositional phrase contained a singular noun library. Hence, the verb should follow the plural form of the subject instead of the singular noun in the prepositional phrase.

The L2 grammatical pattern for subjectverb agreement, although has a simple rule where subject and verb should always be in the synchronized singular or plural form, can appear in various sentence constructions that might confuse the students. As shown in some examples above where the subject-verb agreement occurred in different types of sentences, the students inconsistently applied and omitted the subject-verb agreement pattern in the sentences.

In the students' L1 system, L1 verbs are fixed and do not change according to the number of subject, whether it is singular or plural. Therefore, some possible reasons for the grammatical errors in the form of subjectverb agreement that occurred in the students' descriptive text could possibly be caused by the students' lack of awareness of this L2 rule, or they have not yet fully understood how to apply the grammatical pattern on different types of sentences.

\section{Possessive Cases}

From the data, two students (S1 and S5) made ill-formed sentence construction in the form of possessive case. The ill-formed sentence construction that the students made is listed in Table 8.

Table 8. Incorrect Grammatical Construction in the Form of Possessive Cases

\begin{tabular}{cl}
\hline Student & \multicolumn{1}{c}{ Sentence } \\
\hline S1 & 1. The librarian' name is sir japon. \\
\hline \multirow{3}{*}{ S5 } & 2. My mother age is 57 year old. \\
& $\begin{array}{l}\text { 3. My sister named Dewi. } \\
\text { 4. Her child named Tara. }\end{array}$
\end{tabular}

In sentences 1-2, S1 and S5 made grammatically incorrect sentences by not applying the proper form of possessive to particular nouns. In L2 structure, possessive form is made by adding an apostrophe and an - $s$ after singular nouns and an apostrophe for plural nouns (e.g. singular $\rightarrow$ a student's lunch; plural $\rightarrow$ students' lunch). In the sentences, however, S1 and S5 omitted the use of apostrophe and the suffix $-s$, i.e. librarian' and mother age. Consequently, the sentences became grammatically incorrect. As the nouns in the sentences were singular, the students should have added proper possessive form for singular nouns, i.e. librarian's and my mother's age.

Furthermore, in sentences 3-4, S5 used incorrect form for the possessive and omitted the verbs, thus causing an ill-formed sentence construction in the sentences. A proper construction for sentences 3-4 can be ' $M y$ sister's name is Dewi' and 'Her child's name is Tara'. 
In the students' $\mathrm{L} 1$ system, the possessive form does not include apostrophe and an $-s$ after certain nouns. The L1's possessive form is simply expressed by using pronouns, e.g. her book and his family. This might be one of the reasons why the students made ill-formed sentence construction in the written form of the possessive form.

\section{Grammatical Categories that Occurred the Most and Least Frequently in the Students' Descriptive Text}

From the analysis, the findings show that the students make the most ill-formed sentence construction in the grammatical categories of article and tenses (with total 8 occurrences for each category), followed by concord (7 occurrences) and singular and plural nouns (6 occurrences). As for other grammatical categories, such as adjectives, prepositions and possessive case, the number of incorrect grammatical occurrences is quite low (in total 2-4 occurrences).

The fact that articles, tenses and concord have the highest occurrences in the students' ill-formed sentence construction implies that the students possibly have difficulties in these grammatical categories, chiefly because the L1 and L2 rules for the use of article, tenses and concord are very different. Indonesians tend to ignore and omit the use of article in L1 structure, and this habit is often transferred by Indonesian EFL learners when they are learning L2 (Mustafa et al., 2016). In the term of tenses, Bahasa does not have complex rules to indicate certain tenses; hence, EFL learners, particularly who are still in the beginner or intermediate level, often encounter difficulties in constructing L2 sentences with appropriate tenses. Moreover, in the term of concord, since Bahasa does not change or modify its verbs according to the number of subject (singular or plural), Indonesians do not have the subject-verb agreement rule in their L1 system. Therefore, this L1 system tends to be applied directly without much awareness by EFL learners in L2 writing and potentially causes ill-formed sentence construction.

On the other hand, as the texts produced by the students in this study were descriptive texts, the students used common language features of a descriptive text, particularly adjectives to describe subjects and nouns. It is quite surprising to find that the students did not make major ill-formed sentence constructions in the form of adjectives. This may show that the students in this study have possibly had better understanding on L2 adjectives and have been able to apply them in L2 writing.

\section{Conclusion}

The study examined Indonesian students' descriptive text to investigate the ill-formed sentence construction related to grammatical forms. The findings of this study showed that the incorrect grammatical forms that occurred most frequently in the students' text included article, tenses and concord. On the contrary, the incorrect grammatical forms that occurred the least consisted of adjectives, prepositions and possessive case. Moreover, the ill-formed sentence construction made by the students resulted from omission, addition and selection (Ellis, 1997).

The findings of this study also implied that EFL learners, particularly in the beginner and intermediate levels, still have difficulties in acquiring the $\mathrm{L} 2$ grammatical patterns and in applying them correctly in sentence level. Many instances drawn from the data showed that the students frequently either mixed the L1 and L2 grammatical patterns or generalize their L1 system to have similar patterns with L2 in their writing. This was quite similar to Thai students in Kaweera's (2013) study that reports that Thai students tend to rely on their L1 structure when constructing L2.

Therefore, it is important for L2 teachers to facilitate EFL learners, particularly those in the beginner and intermediate levels, with more grammar lessons to enhance familiarity and comprehension on L2 structure. This can be done by helping EFL learners to increase their awareness of the differences between L1 and L2 grammatical patterns and sentence structure through explicit demonstration and discussion where teachers and learners work together to identify the main similarities and differences that L1 and L2 have on the use of certain grammatical aspect. This would foster 
their understanding that their L1 system may be different with L2 system they are learning, and through a consistent practice, learners may become more aware of this and become more alert and careful in applying L 2 rules in writing.

\section{References}

Afrin, S. (2016). Writing Problems of NonEnglish Major Undergraduate Students in Bangladesh: An Observation. Open Journal of Social Sciences, 4(3), 104-115. doi: 10.4236/jss.2016.43016

Al-Khresheh, M. H. (2016). A Review Study of Error Analysis Theory. International Journal of Humanities and Social Science Research, 2, 49-59.

Davies, P. \& Pearse, E. (2000). Success in English Teaching. Oxford: Oxford University Press.

Ellis, R. \& Barkhuzien, G. (2005). Analysis Learner Language. New York: Oxford University Press.

Ellis, R. (1997). Second Language Acquisition. Oxford: Oxford University Press.

James, C. (1998). Errors in Language Learning and Use: Exploring Error Analysis. New York: Addison Wesley Longman.

Kaweera, C. (2013). Writing Error: A Review of Interlingual and Intralingual Interference in EFL Context. English Language Teaching, 6(7), 9-18.

doi: 10.5539/elt.v6n7p9

Mustafa, F., Kirana, M. \& Ys, S. B. (2016). Errors in EFL writing by junior high students in Indonesia. International Journal of Research Studies in Language Learning, 5(5), 37-50.

doi: 10.5861/ijrsll.2016.1366
Nunan, D. (1999). Second Language Teaching \& Learning. Boston: Heinle ELT.

White, R. \& Arndt, V. (1991). Process Writing. London: Longman Publishing Group. 